Jurnal Media Pertanian Vol. 4 No. 1 Tahun 2019 Hal. 26 - 37

Media Komunikasi Hasil Penelitian dan Review Literatur Bidang Ilmu Agronomi

ISSN print $2503-1279$

ISSN online $2581-1606$

\title{
UJI LAPANG BAHAN ORGANIK MASUKAN RENDAH PADA BERBAGAI METODE APLIKASI PEMUPUKAN MELAUI TANAH DAN DAUN TERHADAP PERTUMBUHAN DAN HASIL KEDELAI (Glicyne max (L.) Merril) DI TANAH ULTISOL
}

\author{
${ }^{1}$ Zul Fahri Gani dan ${ }^{2}$ Nasamsir \\ ${ }^{1}$ Prodi Agroteknologi, Fakultas Pertanian Univ. Jambi \\ Kampus Pinang Masak, Mendalo Darat Jambi. \\ ${ }^{2}$ Prodi Agroteknologi Fakultas Pertanian Univ. Batanghari \\ Jl. Slamet Riyadi, Broni Jambi, 36122. Telp. +62741 60103 \\ e-mail korensponden: nasamsirsamsir@yahoo.co.id
}

\begin{abstract}
The strategy for managing soil and soybean plants on Ultisol land by considering the use of low input technology, needs to be pursued so that soybean farming is sustainable, independent and without having to depend on government-assisted programs. The study aims to examine the effect of low input organic matter on various methods of application of soil and leaf fertilization on the growth and yield of soybean plants in Ultisol so that the best soybean plants are grown and produced. Field tests were carried out at the Jambi University Faculty of Agriculture Experimental Garden, Mendalo Indah Village, Muaro Jambi Regency. The experiment lasted for six months, starting in May - October 2017. The soybean seeds used were Rajabasa varieties treated with organic materials $(0$ to 5 tons $\mathrm{ha}^{-1}$ ) which were tested in various ways the application of inorganic fertilizers through the soil (2/3 doses given during planting and $1 / 3$ dose given when entering the reproductive phase) and fertilization through leaves (morning and evening). Data analysis was carried out through a variety test approach and DNMRT difference test at the level of $\alpha$ 0.05. Based on the results of the experiment, some conclusions can be drawn as follows, 1) giving low input organic matter to soybean plants gives a better influence on the growth and yield of soybean plants which is accompanied by proper application of fertilization applications. 2) giving organic material as much as 5 tons ha-1 accompanied by application of $N, P$, and $K$ fertilizers $2 / 3$ doses and $1 / 3$ dose when entering the reproductive phase accompanied by the application of morning and evening leaf fertilizers giving the highest yield on plant height variable $(57.83 \mathrm{~cm})$, chlorophyll amount $11.99 \mu \mathrm{g} / \mathrm{cm}^{2}$ leaf area and leaf $N$ content $6.21 \%$, plant yield 3.07 tons $\mathrm{ha}^{-}$ ${ }^{1}$ and weight 100 seeds $15.12 \mathrm{~g}$, but variable observations of flowering age, experience a slowdown compared to other fertilizer application methods.

Keywords: Soybeans, Organic matters, Fertilizer Application Techniques
\end{abstract}

\begin{abstract}
Abstrak
Strategi pengelolaan tanah dan tanaman kedelai pada tanah Ultisol dengan mempertimbangkan penggunaan teknologi budidaya masukan rendah (low-input technology), perlu diupayakan agar usahatani kedelai berkelanjutan, mandiri dan tanpa harus bergantung pada program berbantuan dari pemerintah. Penelitian bertujuan untuk menguji pengaruh penggunaan bahan organik masukan rendah
\end{abstract}

Diterbitkan oleh Program Studi Agroteknologi Fakultas Pertanian Universitas Batanghari Jambi Halaman 26 
Jurnal Media Pertanian Vol. 4 No. 1 Tahun 2019 Hal. 26 - 37

Media Komunikasi Hasil Penelitian dan Review Literatur Bidang Ilmu Agronomi ISSN print $2503-1279$

ISSN online $2581-1606$

pada berbagai metode aplikasi pemupukan melalui tanah dan daun terhadap pertumbuhan dan hasil tanaman kedelai di tanah Ultisol sehingga dihasilkan pertumbuhan dan hasil tanaman kedelai terbaik. Uji lapang dilakukan di Kebun Percobaan Fakultas Pertanian Universitas Jambi, Desa Mendalo Indah, Kabupaten Muaro Jambi. Percobaan berlangsung selama enam bulan, mulai bulan Mei Oktober 2017. Benih kedelai yang digunakan adalah varietas Rajabasa yang diberi perlakuan pemberian bahan organik ( 0 sampai 5 ton ha ${ }^{-1}$ ) yang diuji pada berbagai cara aplikasi pemupukan anorganik lewat tanah $(2 / 3$ dosis diberi saat tanam dan $1 / 3$ dosis diberi saat memasuki fase reproduktif) dan pemupukan lewat daun (pagi dan sore hari). Analisis data dilakukan melalui pendekatan uji ragam dan uji beda DNMRT pada taraf $\alpha$ 0.05. Berdasarkan hasil percobaan dapat ditarik beberapa kesimpulan sebagai berikut, 1) Pemberian bahan organik masukan rendah pada tanaman kedelai memberikan pengaruh yang lebih baik terhadap pertumbuhan dan hasil tanaman kedelai yang disertai dengan cara aplikasi pemupukan yang tepat. 2) Pemberian bahan organik sebanyak 5 ton $\mathrm{ha}^{-1}$ yang diiringi dengan pemberian pupuk N,P, dan $\mathrm{K} 2 / 3$ dosis saat tanam dan 1/3 dosis saat memasuki fase reproduktif yang disertai pemberian pupuk daun pagi dan sore hari memberikan hasil tertinggi pada variabel tinggi tanaman $(57,83 \mathrm{~cm})$, jumlah klorofil 11,99 $\mu \mathrm{g} / \mathrm{cm}^{2}$ luas daun dan kandungan $\mathrm{N}$ daun $6,21 \%$, hasil tanaman 3,07 ton ha ${ }^{-1}$ serta bobot 100 butir biji $15,12 \mathrm{~g}$, tetapi variabel pengamatan umur berbunga, mengalami perlambatan dibanding cara aplikasi pemupukan lainnya.

Kata Kunci: Kedelai, Bahan Organik, Teknik Aplikasi Pupuk

\section{PENDAHULUAN}

Rencana program perluasan areal tanam kedelai di Provinsi Jambi dihadapkan dengan tanah-tanah suboptimal yang bermasalah dalam hal kesuburan tanahnya, seperti tanah Ultisol. Peruntukan bagi program perluasan areal tanam kedelai sebagian besar juga bertumpu pada potensi tanah Ultisol tersebut, yakni ditargetkan sekitar 12.000 ha (Dinas Pertanian Tanaman Pangan, 2015).

Hampir semua tanaman semusim kurang baik pertumbuhannya di tanah Ultisol (Taufiq dan Sundari, 2012). Supaya kondusif bagi tanaman semusim seperti kedelai, tanah ini membutuhkan teknologi budidaya masukan tinggi (highinput technology) dalam pembenahannya, misalnya memberikan tambahan input bahan organik dalam jumlah banyak agar produktivitas yang dicapai sesuai dengan harapan (Prasetyo dan Suriadikarta, 2006). Teknologi ini tentunya akan berimplikasi pada biaya input usahatani yang akan lebih tinggi. Besarnya input bahan organik yang dibutuhkan untuk memperbaiki kesuburan tanah Ultisol bukan lagi tergolong input biaya murah, sedangkan pada tanah-tanah subur, input bahan organik tidak mutlak diperlukan. Hal ini merupakan perbedaan budidaya tanaman pada dua jenis tanah tersebut.

Penggunaan bahan organik dalam jumlah cukup besar tercermin dari beberapa hasil penelitian yang pernah dilaporkan. Bertham (2002) melaporkan hasil tanaman kedelai yang ditanam di tanah Ultisol mencapai 22,92 g per tanaman (setara 3,82 $\mathrm{t} \mathrm{ha}^{-1}$ ) yang dipupuk urea $75 \mathrm{~kg} \mathrm{ha}^{-1}, \mathrm{~K}_{2} \mathrm{O} 150 \mathrm{~kg} \mathrm{ha}^{-1}$ dan $\mathrm{P}_{2} \mathrm{O}_{5} 225 \mathrm{~kg} \mathrm{ha}^{-1}$ dengan menambahkan bahan organik kompos jerami padi 
Jurnal Media Pertanian Vol. 4 No. 1 Tahun 2019 Hal. 26 - 37

Media Komunikasi Hasil Penelitian dan Review Literatur Bidang Ilmu Agronomi ISSN print $2503-1279$

ISSN online $2581-1606$

sebanyak $45 \mathrm{t} \mathrm{ha}^{-1}$. Kastono (2005) melaporkan bahwa pemberian Urea $50 \mathrm{~kg} \mathrm{ha}^{-1}$, TSP dan $\mathrm{KCl}$ masing-masing $100 \mathrm{~kg} \mathrm{ha}^{-1}$ pada tanaman kedelai di tanah Ultisol, mencapai hasil sebanyak 2,78 $\mathrm{t} \mathrm{ha}^{-1}$ jika diiringi dengan pemberian bahan organik $30 \mathrm{t} \mathrm{ha}^{-1}$. Dari dua laporan hasil penelitian tersebut di atas, jika tanpa pemberian bahan organik, hasil kedelai yang dicapai kurang dari $1 \mathrm{t} \mathrm{ha}^{-1}$. Hasil penelitian tersebut membuktikan pentingnya input bahan organik di tanah Ultisol, agar hasil panen bisa sama atau mendekati potensi hasil varietas unggul yang dicobakan.

Mengingat kebutuhan bahan organik yang sedemikian besarnya, budidaya kedelai di tanah Ultisol tidak lagi rasional terkait beban biaya yang sangat memberatkan petani yang umumnya terkendala dalam hal permodalan, sehingga usahatani dilaksanakan seadanya saja dengan hasil panen yang rendah. Kondisi ini yang menyebabkan mengapa target swasembada kedelai yang sudah beberapa kali dicanangkan pemerintah selalu mengalami kegagalan (Budhi dan Mimin, 2010). Berkaitan dengan persoalan tersebut, maka perlu dipikirkan strategi pengelolaan tanah dan tanaman kedelai pada tanah Ultisol, tetapi dengan mempertimbangkan penggunaan teknologi budidaya masukan rendah (low-input technology). Tujuannya agar usahatani kedelai berkelanjutan, mandiri dan tanpa harus bergantung pada program berbantuan dari pemerintah.

Input bahan organik rendah memang menimbulkan masalah pada tanah Ultisol karena menurunnya serapan hara dari pupuk anorganik yang diberikan. Oleh karena itu tidak dianjurkan pemberian pupuk anorganik sekaligus pada awal tanam. Untuk meningkatkan efisiensi penggunaan pupuk anorganik disarankan pemberiannya dua tahap, yakni sebagian diberikan bersamaan dengan waktu tanam dan sisanya sebagai pupuk susulan (Pusat Penelitian Tanah dan Agroklimat, 2011). Pengaturan waktu dan dosis pemberian harus disesuaikan dengan jenis tanaman dan fase pertumbuhannya. Penerapan metode pemberian pupuk seperti ini lebih efisien dibanding diberikan sekaligus diawal tanam (Lamon dan Wesley, 2001).

Hasil uji lapang pada beberapa lokasi di tanah Ultisol membuktikan keunggulan budidaya kedelai dengan adanya pemberian pupuk susulan. Pusat Penelitian Tanah dan Agroklimat (2011) melaporkan bahwa pemberian pupuk Urea sebanyak 25 - $50 \mathrm{~kg}$, SP36 200 - $250 \mathrm{~kg}$ dan $\mathrm{KCl}$ sebanyak 100 - $150 \mathrm{~kg}$ per hektar sudah memadai. Cara aplikasinya yakni, 2/3 dosis saat tanam dan sisanya $1 / 3$ dosis sebagai pupuk susulan yang diberikan pada saat tanaman kedelai memasuki fase reproduktif (masa mulai berbunga). Sedangkan jika pemberian bahan organik dilakukan, tujuannya hanya sebatas memperbaiki kesuburan biologis tanah.

Margiati et al., (2014) melaporkan hasil tanaman kedelai varietas Rajabasa yang diberi pupuk kompos sampah kota sebanyak $6 \mathrm{t} \mathrm{ha}^{-1}$ pada dua metode aplikasi pupuk anorganik berbeda. Hasil tertinggi dicapai jika 2/3 dosis diberikan saat tanam dan $1 / 3$ dosis dari pupuk anorganik diberikan sebagai pupuk susulan, yakni mencapai hasil panen sebesar 1,57 $\mathrm{t} \mathrm{ha}^{-1}$. Apabila pupuk anorganik diberikan seluruhnya saat tanam, hasil yang dicapai lebih rendah sekitar 33,4\%. Hasil panen yang dilaporkan ini masih jauh di bawah daya hasil genetisnya. Berdasarkan laporan Badan Penelitian dan Pengembangan Pertanian (2016), varietas Rajabasa merupakan salah satu varietas unggul kedelai yang sangat

Diterbitkan oleh Program Studi Agroteknologi Fakultas Pertanian Universitas Batanghari Jambi Halaman 28 
Jurnal Media Pertanian Vol. 4 No. 1 Tahun 2019 Hal. 26 - 37

Media Komunikasi Hasil Penelitian dan Review Literatur Bidang Ilmu Agronomi ISSN print $2503-1279$

ISSN online $2581-1606$

adaptif pada lahan kering masam maupun di lahan tanah gambut. Varietas ini mempunyai daya hasil yang tinggi, mencapai $3,9 \mathrm{t} \mathrm{ha}^{-1}$, serta bobot 100 butir biji kering rata-rata $15 \mathrm{~g}$.

Masih dari hasil penelitian Margiati et al., (2014), serapan hara N, P, dan $\mathrm{K}$ yang diberi bahan organik dosis rendah ternyata tidak memadai. Hal ini terdeteksi dari rendahnya hara tersebut pada daun, yakni untuk $\mathrm{N}$ berkisar antara 4,23-4,48 \%, untuk P berkisar antara 0,16-0,21 \% dan $\mathrm{K}$ berkisar antara 1,35-1,68 $\%$. Rosmarkam dan Yuwono (2002) menyatakan bahwa serapan hara N, P dan K tanaman kedelai dikatakan cukup jika status hara yang dideteksi pada daun mencapai kisaran 4,51 - 5,5\% untuk N, 0,26-0,50\% untuk P dan 1,72 - 2,50\% untuk K. Jika serapan hara tidak mencukupi sesuai kebutuhan tanaman, maka hasil panen tidak akan optimal.

Menurut Franzen (1999), rendahnya serapan hara tersebut merupakan masalah yang timbul dari inefisiensi pemupukan. Pada tanaman kedelai, masalah ini tidak hanya bersumber dari sifat jelek tanah Ultisolnya saja, tapi juga berkaitan dengan fenomena fisiologis yang terjadi pada tanaman kedelai. Jika permasalahan budidaya di tanah Ultisol tidak bisa dipecahkan secara menyeluruh, bagi petani sudah cukup bila ada paket teknologi budidaya murah tapi bisa mendatangkan keuntungan yang lebih layak. Salah satu terobosan yang memungkinkan untuk hal tersebut adalah menekan penggunaan bahan organik serta meningkatkan efisiensi pemupukan anorganik. Untuk mengatasi rendahnya serapan hara sebagaimana diuraikan di atas, pemberian pupuk tambahan melalui daun perlu dipertimbangkan.

Menurut Boote et al., (1979), beberapa alasan yang melandasi pentingnya pemupukan lewat daun antara lain bila kondisi lingkungan membatasi penyerapan unsur hara oleh akar. Keadaan seperti ini merupakan masalah yang umum terjadi pada tanah-tanah masam seperti Ultisol. Alasan lainnya menurut Jhon dan David (2001), adalah menurunnya respon tanaman kedelai terhadap pupuk susulan yang diberikan lewat tanah ketika memasuki fase reproduktif (masa berbunga). Sedangkan tanaman kedelai membutuhkan unsur hara yang cukup dari fase berbunga hingga fase pembentukan dan pengisian biji. Zamski (1996) menerangkan hal ini sebagai akibat dari fenomena fisiologis yang terjadi dalam perkembangan tanaman kedelai. Pertumbuhan akar mulai tertekan saat memasuki fase reproduktif karena penggunaan foto asimilat sebagian besar diarahkan untuk pembentukan bunga, polong, dan biji. Oleh karenanya, Garcia dan Hanway (1985) menjelaskan bahwa pemupukan melalui daun pada periode pembungaan merupakan waktu yang tepat untuk meningkatkan hasil biji kedelai.

Berdasarkan permasalahan yang telah diuraikan di atas, dirasa perlu melakukan suatu terobosan yang dapat dijadikan sebagai solusi mengatasi permasalahan budidaya Kedelai di tanah Ultisol. Berkaitan dengan itu, salah satu aspek yang perlu dikaji adalah "Uji Lapang Bahan Organik Masukan Rendah Pada Berbagai Metode Aplikasi Pemupukan Melalui Tanah dan Daun Terhadap Pertumbuhan dan Hasil Kedelai (Glycine max (L.) Merril) di Tanah Ultisol.

Tujuan dari penelitian ini adalah untuk mengetahui pengaruh penggunaan bahan organik masukan rendah pada berbagai metode aplikasi pemupukan melalui tanah dan daun terhadap pertumbuhan dan hasil tanaman kedelai di tanah Ultisol. 
Jurnal Media Pertanian Vol. 4 No. 1 Tahun 2019 Hal. 26 - 37

Media Komunikasi Hasil Penelitian dan Review Literatur Bidang Ilmu Agronomi ISSN print $2503-1279$

ISSN online $2581-1606$

Untuk itu akan dapat diketahui pertumbuhan dan hasil tanaman kedelai terbaik dari bahan organik masukan rendah yang diberikan pada berbagai metode aplikasi pemupukan yang dicobakan.

\section{METODE PENELITIAN}

Uji lapang dilakukan di Kebun Percobaan Fakultas Pertanian Universitas Jambi, Desa Mendalo Indah, Kabupaten Muaro Jambi. Percobaan berlangsung selama enam bulan, mulai Bulan Mei - Oktober 2017. Bahan yang diperlukan untuk percobaan meliputi; benih kedelai varietas Rajabasa, bahan organik kotoran kandang ayam, pupuk Urea, SP36 dan KCl, inokulum Rhizobim, alat tulis dan lainnya. Peralatan yang digunakan meliputi; alat ukur (meteran dan timbangan), hand sprayer, ember, cuter, alat siram dan lainnya.

Rancangan lapangan yang digunakan dalam uji lapang ini adalah Rancangan Acak kelompok (RAK) yang diulang 3 (tiga) kali, sedangkan perlakuan yang dicobakan terdiri dari pemberian bahan organik dengan dosis rendah (0 (b0), 2,5 (b1) dan 5,0 ton ha $\left.^{-1}(\mathrm{~b} 2)\right)$ yang dikombinasikan dengan dua cara aplikasi pemupukan N,P, dan K (aplikasi bersamaan tanam (k1) dan 2/3 dosis diberikan saat tanam, 1/3 dosis diberikan menjelang tanaman kedelai memasuki fase reproduktif (k2). serta diberi pupuk daun pagi hari (f1) dan pagi dan sore hari (f2). Aplikasi pupuk daun seminggu sekali mulai minggu ke-5 sampai minggu ke8. Dari rancangan perlakuan ini diperoleh sebanyak 12 kombinasi perlakuan dengan pengkodean perlakuan di lapangan mulai P1 sampai P12, yakni ;

$\mathrm{P} 1$ = Tanpa pupuk kandang (b0), pupuk NPK seluruhnya saat tanam (k1), pupuk daun diberikan pagi hari saja (f1).

$\mathrm{P} 2$ = Tanpa pupuk kandang (b0), pupuk NPK $2 / 3$ dosis saat tanam dan $1 / 3$ dosis pupuk susulan (k2), pupuk daun diberikan pagi hari saja (f1).

P3 = Pupuk kandang 2,5 $\mathrm{t} \mathrm{ha}^{-1}$ (b1), pupuk NPK seluruhnya saat tanam (k1), pupuk daun diberikan pagi hari saja (f1).

P4 =Pupuk kandang 2,5 $\mathrm{t} \mathrm{ha}^{-1}$ (b1), pupuk NPK 2/3 dosis saat tanam dan 1/3 dosis pupuk susulan (k2), pupuk daun diberikan pagi hari saja (f1).

P5 = Pupuk kandang $5 \mathrm{t} \mathrm{ha}^{-1}$ (b3), pupuk NPK seluruhnya saat tanam (k1), pupuk daun diberikan pagi hari saja (f1).

P6 = Pupuk kandang $5 \mathrm{t} \mathrm{ha}^{-1}$ (b3), pupuk NPK 2/3 dosis saat tanam dan 1/3 dosis pupuk susulan (k2), pupuk daun diberikan pagi hari saja (f1).

P7= Tanpa pupuk kandang (b0), pupuk NPK seluruhnya saat tanam (k1), pupuk daun diberikan pagi dan sore hari (f2).

$\mathrm{P} 8$ = Tanpa pupuk kandang (b0), pupuk NPK 2/3 dosis saat tanam dan 1/3 dosis pupuk susulan (k2), pupuk daun diberikan pagi dan sore hari (f2).

P9 = Pupuk kandang 2,5 $\mathrm{t} \mathrm{ha}^{-1}$ (b1), pupuk NPK seluruhnya saat tanam (k1), pupuk daun diberikan pagi dan sore hari (f2).

P10 = Pupuk kandang 2,5 $\mathrm{t} \mathrm{ha}^{-1}$ (b2), pupuk NPK 2/3 dosis saat tanam dan 1/3 dosis pupuk susulan (k2), pupuk daun diberikan pagi dan sore hari (f2).

P11 = Pupuk kandang $5 \mathrm{t} \mathrm{ha}^{-1}(\mathrm{~b} 3)$, pupuk NPK seluruhnya saat tanam (k1), pupuk daun diberikan pagi dan sore hari (f2).

P12 = Pupuk kandang $5 \mathrm{t} \mathrm{ha}^{-1}$ (b3), pupuk NPK 2/3 dosis saat tanam dan 1/3 dosis pupuk susulan (k2), pupuk daun diberikan pagi dan sore hari (f2).

Diterbitkan oleh Program Studi Agroteknologi Fakultas Pertanian Universitas Batanghari Jambi Halaman 30 
Jurnal Media Pertanian Vol. 4 No. 1 Tahun 2019 Hal. 26 - 37

Media Komunikasi Hasil Penelitian dan Review Literatur Bidang Ilmu Agronomi ISSN print $2503-1279$

ISSN online $2581-1606$

Teknik analisis data yang digunakan adalah Uji Ragam dan Uji DNMRT pada taraf $\alpha_{0,05}$. berikut:

Rancangan respon yang diamati dalam penelitian ini adalah sebagai

1. Variabel pertumbuhan, yaitu pengamatan tinggi tanaman $(\mathrm{cm})$, diamati pada akhir penelitian.

2. Pengamatan umur berbunga (hari setelah tanam), diamati pada akhir minggu ke-4 setelah tanam (awal minggu ke-2 pada bulan ke-3 penelitian).

3. Pengamatan kandungan klorofil dan status hara $\mathrm{N}$ yang diamati pada minggu ke-9 setelah tanam (minggu ke-2 pada bulan ke-4 penelitian).

4. Pengukuran hasil (ton/ha), dilakukan pada pertengahan minggu ke-14 setelah tanam (pertengahan minggu ke-3 pada bulan ke-5 penelitian).

5. Pengukuran jumlah 100 butir biji kering (g), dilakukan minggu ke-1 pada bulan ke-6 penelitian.

\section{HASIL DAN PEMBAHASAN}

Hasil uji lapang terhadap perlakuan yang dicobakan, diukur pada beberapa variabel pengamatan sebagai berikut.

\section{Tinggi Tanaman Kedelai}

Hasil analisis statitistik menujukkan perlakuan yang diuji berbeda efek terhadap tinggi tanaman kedelai yang dapat dilihat pada tabel di bawah ini Tabel 1. Efek Perlakuan Terhadap Tinggi Tanaman Kedelei Umur 24 MST

\begin{tabular}{|c|c|}
\hline Perlakuan & Tinggi Tanaman (cm) \\
\hline P1 & $43,45 \mathrm{a}$ \\
P2 & $45,67 \mathrm{a}$ \\
P3 & $45,31 \mathrm{a}$ \\
P4 & $47,87 \mathrm{ab}$ \\
P5 & $49,23 \mathrm{~b}$ \\
P6 & $49,89 \mathrm{bc}$ \\
P7 & $52,16 \mathrm{c}$ \\
P8 & $51,95 \mathrm{~cd}$ \\
P9 & $54,65 \mathrm{~d}$ \\
P10 & $54,36 \mathrm{de}$ \\
P11 & $56,91 \mathrm{ef}$ \\
P12 & $57,83 \mathrm{f}$ \\
\hline
\end{tabular}

Keterangan : Angka-angka yang diikuti huruf kecil yang sama tidak berbeda nyata pada taraf $\alpha 0,05$ DNMRT.

Berdasarkan hasil uji DNMRT pada taraf $\alpha 0,05$, tinggi tanaman tertinggi diperoleh dari perlakuan P12, yakni tanaman kedele yang diberi bahan organik sebanyak 5 ton ha $^{-1}$ yang diberi pupuk N,P, dan K 2/3 dosis saat tanam dan 1/3 dosis sebagai pupuk susulan yang disertai dengan pemberian pupuk daun pagi dan sore hari. Hasil ini memang tidak berbeda dibanding jika aplikasi pupuk N,P, dan K sekaligus pada saat tanam. 
Jurnal Media Pertanian Vol. 4 No. 1 Tahun 2019 Hal. 26 - 37

Media Komunikasi Hasil Penelitian dan Review Literatur Bidang Ilmu Agronomi ISSN print $2503-1279$

ISSN online $2581-1606$

\section{Umur Berbunga}

Pengamatan terhadap umur berbunga juga berbeda sebagai akibat perbedaan jumlah bahan organik yang diaplikasikan dengan berbagai cara pemupukan yang berbeda yang dapat dilihat pada Tabel 2 .

Terlihat kecenderungan meningkatnya umur berbunga tanaman kedelai yang diberi bahan organik lebih banyak. Umur berbunga lebih lama dijumpai pada tanaman kedelai yang diberi bahan organik 5 ton ha ${ }^{-1}$ yang dipupuk N,P, dan K $2 / 3$ dosis bersamaan tanam dan $1 / 3$ dosis sebagai pupuk susulan yang diberikan pada saat tanaman kedelai memasuki fase reproduktif.

Tabel 2. Efek Perlakuan Terhadap Umur Berbunga Tanaman Kedelei

\begin{tabular}{|c|c|}
\hline Perlakuan & Umur Berbunga (hari) \\
\hline P1 & $31,4 \mathrm{a}$ \\
P2 & $31,7 \mathrm{a}$ \\
P3 & $33,2 \mathrm{ab}$ \\
P4 & $33,5 \mathrm{~b}$ \\
P5 & $33,8 \mathrm{~b}$ \\
P6 & $34,5 \mathrm{~b}$ \\
P7 & $34,7 \mathrm{~b}$ \\
P8 & $34,7 \mathrm{bc}$ \\
P9 & $34,9 \mathrm{c}$ \\
P10 & $35,1 \mathrm{c}$ \\
P11 & $35,3 \mathrm{c}$ \\
P12 & $35,5 \mathrm{c}$ \\
\hline
\end{tabular}

Keterangan : Angka-angka yang diikuti huruf kecil yang sama tidak berbeda nyata pada taraf $\alpha 0,05$ DNMRT.

Fenomena meningkatnya umur berbunga pada tanaman kedelai menjelaskan adanya perlambatan memasuki fase reproduktif. Diduga hal ini bisa terjadi karena pengaruh status hara tanaman yang meningkat, misalnya hara $\mathrm{N}$. Sebagaimana dikemukakan Brevedans, et al., (1981), meningkatnya jumlah $\mathrm{N}$ dalam tanaman dapat memperpanjang fase vegetatif tanaman kedelai. Selanjutnya dijelaskan bahwa meski fase vegetatif tanaman kedelai lebih panjang dengan bertambahnya kandungan $\mathrm{N}$ dalam tanaman, sampai batas jumlah tertentu justru memberi efek yang lebih baik bagi pertumbuhan dan hasil tanaman Kedelai.

\section{Jumlah Klorofil dan Status Hara N Tanaman}

Pengamatan pada kandungan klorofil dan $\mathrm{N}$ daun juga semakin meningkat dengan bertambahnya suplai bahan organik yang diberikan pada tanaman kedelai. Baik kandungan klorofil maupun kandungan $\mathrm{N}$ daun, tertinggi diperoleh pada perlakuan P12, yakni yang diberi bahan organik 5 ton ha ${ }^{-1}$ yang disertai dengan pemupukan N,P dan $\mathrm{K} 2 / 3$ dosis saat tanam dan 1/3 dosis sebagai susulan. Sedangkan aplikasi pupuk daunnya adalah pagi dan sore hari. Kecenderungan perubahan kandungan klorofil dan $\mathrm{N}$ daun dicantumkan pada Tabel 3. Dari tabel tersebut dapat dijelaskan suatu hubungan yang secara korelatif positif antara peningkatan kandungan $\mathrm{N}$ daun dengan klorofil daun. Semakin tinggi kandungan $\mathrm{N}$ daun juga semakin meningkatkan kandungan klorofil daun. Sebagaimana

Diterbitkan oleh Program Studi Agroteknologi Fakultas Pertanian Universitas Batanghari Jambi Halaman 32 
Jurnal Media Pertanian Vol. 4 No. 1 Tahun 2019 Hal. 26 - 37

Media Komunikasi Hasil Penelitian dan Review Literatur Bidang Ilmu Agronomi ISSN print $2503-1279$

ISSN online $2581-1606$

dijelaskan Zapata et al., (1987), peningkatan kandungan $\mathrm{N}$ tanaman terdeteksi pertama sekali pada peningkatan klorofil daun. Begitu juga penurunan kandungan $\mathrm{N}$ tanaman akan tampak pertama sekali pada penurunan kandungan klorofil pada daun. Hal ini akan terlihat gejala menguningnya daun akibat pembentukan klorofil pada daun berkurang.

Tabel 3. Efek Perlakuan Terhadap Kandungan Klorofil dan N pada Daun Kedelai (9 MST)

\begin{tabular}{|c|c|c|c|}
\hline Perlakuan & $\begin{array}{c}\text { Jumlah Klorofil } \\
\left(\boldsymbol{\mu g} / \mathbf{c m}^{\mathbf{2}} \text { luas daun }\right)\end{array}$ & $\begin{array}{c}\text { Kandungan N } \\
\text { Daun }(\boldsymbol{\%})\end{array}$ & Status Hara N \\
\hline P1 & $8,94 \mathrm{a}$ & $3,81 \mathrm{a}$ & Sangat Rendah \\
P2 & $8,87 \mathrm{a}$ & $3,86 \mathrm{a}$ & Sangat Rendah \\
P3 & $9,85 \mathrm{ab}$ & $3,99 \mathrm{ab}$ & Sangat Rendah \\
P4 & $9,81 \mathrm{~b}$ & $4,31 \mathrm{~b}$ & Rendah \\
P5 & $10,11 \mathrm{bc}$ & $4,39 \mathrm{~b}$ & Rendah \\
P6 & $10,34 \mathrm{~cd}$ & $4,35 \mathrm{~b}$ & Rendah \\
P7 & $10,76 \mathrm{de}$ & $4,41 \mathrm{~b}$ & Rendah \\
P8 & $10,87 \mathrm{ef}$ & $4.48 \mathrm{bc}$ & Rendah \\
P9 & $11,33 \mathrm{f}$ & $4,67 \mathrm{~cd}$ & Sedang \\
P10 & $11,48 \mathrm{fg}$ & $5,30 \mathrm{~d}$ & Sedang \\
P11 & $11,86 \mathrm{gh}$ & $5,58 \mathrm{de}$ & Tinggi \\
P12 & $11,99 \mathrm{~h}$ & $6,21 \mathrm{e}$ & Tinggi \\
\hline
\end{tabular}

Keterangan : Angka-angka yang diikuti huruf kecil yang sama tidak berbeda nyata pada taraf $\alpha 0,05$ DNMRT.

Terlihat pada tabel di atas, perubahan status hara $\mathrm{N}$ daun tanaman kedelai dari sangat rendah sampai tinggi. Kriteria tersebut mengacu pada status hara yang dikemukakan Rosmarkam dan Yuwono (2002). Kriteria kecukupan hara N tersebut juga berkaitan dengan kondisi pertumbuhan tanaman dan hasil panen tanaman kedelai yang diperoleh.

\section{Hasil Tanaman}

Hasil panen tanaman kedelai juga mengikuti pola peningkatan yang sama dengan variabel pengamatan lainnya. Penambahan dosis bahan organik dengan aplikasi N,P, dan K 1/3 dosis sebagai pupuk susulan dan pemberian pupuk daun pagi dan sore hari semakin meningkatkan hasil panen tanaman kedelai. Tabel 4 menunjukkan, hasil panen tertinggi dicapai dari pemberian bahan organik sebanyak 5 ton ha $^{-1}$, yang dipupuk N.P, dan K 2/3 dosis saat tanam dan $1 / 3$ dosis sebagai pupuk susulan, dan pupuk daun diberikan pagi dan sore hari. Meningkatnya hasil panen tentu berkaitan dengan peningkatan dosis bahan organik yang diberikan serta cara aplikasi pupuk yang diberikan. Meskipun dosis bahan organik yang diberikan relatif rendah, peranannya menjadi sangat efektif karena diiringi dengan cara pemberian pupuk yang lebih efisien. Menurut Hardjowigeno (2010), pemberian pupuk pada tanah dengan mengatur cara pemberiannya akan lebih optimal diserap tanaman, misalnya dengan memberi $2 / 3$ dosis saat tanam dan $1 / 3$ dosis sebagai pupuk susulan yang disesuaikan pemberiannya dengan fase tumbuh tanaman. Cara pemberian pupuk secara 
Jurnal Media Pertanian Vol. 4 No. 1 Tahun 2019 Hal. 26 - 37

Media Komunikasi Hasil Penelitian dan Review Literatur Bidang Ilmu Agronomi ISSN print $2503-1279$

ISSN online $2581-1606$

bertahap tersebut untuk menghindari terjadinya kehilangan hara yang lebih besar dari dalam tanah sebelum diserap oleh akar tanaman. Franzen (1999) mempertegas bahwa pemberian pupuk susulan pada kedelai jangan sampai pertumbuhan Kedelai telah memasuki fase reproduktif.

Tabel 4.Efek Perlakuan Terhadap Hasil Panen Tanaman Kedelai

\begin{tabular}{|c|c|}
\hline Perlakuan & Hasil Tanaman $\left(\right.$ ton $\left.\mathbf{~ h a}^{-1}\right)$ \\
\hline P1 & $1,85 \mathrm{a}$ \\
P2 & $1,89 \mathrm{a}$ \\
P3 & $1,99 \mathrm{a}$ \\
P4 & $2,03 \mathrm{a}$ \\
P5 & $2,15 \mathrm{a}$ \\
P6 & $2,14 \mathrm{ab}$ \\
P7 & $2,35 \mathrm{~b}$ \\
P8 & $2,56 \mathrm{~b}$ \\
P9 & $2,59 \mathrm{bc}$ \\
P10 & $2,63 \mathrm{~cd}$ \\
P11 & $2,82 \mathrm{de}$ \\
P12 & $3,07 \mathrm{e}$ \\
\hline
\end{tabular}

Keterangan : Angka-angka yang diikuti huruf kecil yang sama tidak berbeda nyata pada taraf $\alpha 0,05$ DNMRT.

Efek positif pemberian pupuk daun pada tanaman kedelai untuk mengatasi masalah perkembangan akar yang mulai terhambat pada saat memasuki fase reproduktif. Hal ini akan menyebabkan serapan hara yang diberikan melalui tanah menurun secara drastis (Boote et al., 1979). Terlihat dari tabel di atas bahwa hasil panen tertinggi diperoleh pada perlakuan P12, yakni tanaman kedelai yang diberi bahan organik 5 ton $\mathrm{ha}^{-1}$ yang diiringi dengan pengaturan pemberian $\mathrm{N}, \mathrm{P}$, dan $\mathrm{K}$ secara susulan serta pemberian pupuk daun pagi dan sore hari. Hasil panen Kedelai yang diperoleh pada perlakuan ini mencapai 3,07 ton $\mathrm{ha}^{-1}$. Perolehan hasil sebesar 3,07 ton $\mathrm{ha}^{-1}$ memang masih lebih rendah dibanding daya hasil varietas Rajabasa yang digunakan dalam percobaan ini $\left(3,9\right.$ ton $\left.\mathrm{ha}^{-1}\right)$, namun kenaikan hasil ini cukup menggembirakan tentunya dibanding hasil panen kedelai yang dicapai dari pemberian bahan organik dengan cara aplikasi pupuk anorganik lainnya.

\section{Bobot 100 Butir Biji}

Hasil uji statistika juga menunjukkan adanya efek yang berbeda dari setiap perlakuan yang dicobakan terhadap bobot 100 butir biji. Perbedaan tersebut disajikan pada Tabel 5. Berdasarkan hasil pengamatan yang disajikan pada Tabel 5 , terdapat pola respon yang sama antara peningkatan bobot 100 butir biji dengan peningkatan pertumbuhan tanaman, kandungan klorofil dan status hara $\mathrm{N}$ daun serta hasil panen tanaman kedelai. Status hara $\mathrm{N}$ daun yang tinggi telah mendorong pembentukan klorofil lebih banyak. Hal ini dapat memicu aktivitas fotosintesis yang lebih tinggi. Pada gilirannya, menurut Zamski (1996) akan meningkatkan distribusi fotosintat ke bagian organ-organ sink (pengguna) yang dapat meningkatkan pertumbuhan tanaman dan hasil tanaman kedelai.

Diterbitkan oleh Program Studi Agroteknologi Fakultas Pertanian Universitas Batanghari Jambi Halaman 34 
Jurnal Media Pertanian Vol. 4 No. 1 Tahun 2019 Hal. 26 - 37

Media Komunikasi Hasil Penelitian dan Review Literatur Bidang Ilmu Agronomi ISSN print $2503-1279$

ISSN online $2581-1606$

Tabel 5. Efek Perlakuan Terhadap Bobot 100 Butir Biji

\begin{tabular}{|c|c|}
\hline Perlakuan & Bobot 100 Butir Biji (g) \\
\hline P1 & $12,31 \mathrm{a}$ \\
P2 & $12,45 \mathrm{a}$ \\
P3 & $12,36 \mathrm{ab}$ \\
P4 & $12,51 \mathrm{~b}$ \\
P5 & $12,86 \mathrm{~b}$ \\
P6 & $12,94 \mathrm{bc}$ \\
P7 & $13,21 \mathrm{c}$ \\
P8 & $13,44 \mathrm{c}$ \\
P9 & $13,92 \mathrm{~cd}$ \\
P10 & $14,28 \mathrm{~d}$ \\
P11 & $14,76 \mathrm{de}$ \\
P12 & $15,12 \mathrm{e}$ \\
\hline
\end{tabular}

Keterangan : Angka-angka yang diikuti huruf kecil yang sama tidak berbeda nyata pada taraf $\alpha 0,05$ DNMRT.

Dari tabel di atas juga terlihat bahwa perlakuan P12 menghasilkan ukuran biji yang lebih besar sehingga kualitasnya lebih baik. Diduga hal ini berkaitan dengan aplikasi pemupukan yang diuji lebih efektif dalam meningkatkan serapan hara tanaman kedelai.

Pemberian pupuk organik merupakan tindakan yang diharapkan dapat memperbaiki tingkat kesuburan tanah melalui perbaikan sifat fisik, kimia, dan biologi tanah. Beberapa penelitian menunjukkan, pemberian pupuk organik dapat meningkatkan efisiensi pemberian pupuk anorganik yang pada akhirnya meningkatkan produksi yang maksimal. Pemberian bahan organik dan pupuk anorganik (N,P,dan $\mathrm{K})$ merupakan usaha dalam memenuhi kebutuhan unsur hara tanaman. Menurut Leiwakabessy et.al.(2003), bahan organik berfungsi untuk (1) memperbaiki struktur tanah, (2) menambah ketersediaan unsur N,P,dan S, (3) meningkatkan kemampuan tanah mengikat air, (4) memperbesar kapasitas tukar kation (KTK), dan (5) mengaktifkan mikroorganisme tanah. Penelitian lain juga menunjukkan pemberian bahan organik dan pupuk anorganik dapat meningkatkan pH tanah, N-total, P-tersedia, dan K-tersedia di dalam tanah, kadar dan serapan hara $\mathrm{N}, \mathrm{P}$,dan $\mathrm{K}$ tanaman dan meningkatkan hasil tanaman jagung (Djuniwati et.al. 2003) serta produksi tanaman kedelei (Hermawan, 2002)

Sistem Pertanian organik mempunyai kemampuan untuk menyediakan N lebih tinggi dibanding sistem pertanian konvensional, karena pupuk organik merupakan sumber $\mathrm{N}$, sehingga pemberian pupuk organik meningkatkan kandungan $\mathrm{N}$ pada jaringan tanaman. Adanya perbaikan sifat fisik tanah dan ketersediaan $\mathrm{N}$ yang cukup, maka kontak bulu akar pada sistem pertanian semiorganik lebih dekat, sehingga unsur hara yang dapat diserap juga lebih banyak. Hal ini sejalan dengan hasil penelitian yang dilakukan, bahwa terjadi peningkatan kandungan $\mathrm{N}$ daun dan jumlah klorofil daun tanaman kedelei dari perlakuan pemberian bahan organik dibanding tanpa bahan organik.

Di sisi lain, adanya senyawa organik yang berasal dari pupuk organik berperan membantu pelarutan atau pelepasan $\mathrm{P}$ yang terikat oleh $\mathrm{Fe}$ dan $\mathrm{Al}$

Diterbitkan oleh Program Studi Agroteknologi Fakultas Pertanian Universitas Batanghari Jambi Halaman 35 
Jurnal Media Pertanian Vol. 4 No. 1 Tahun 2019 Hal. 26 - 37

Media Komunikasi Hasil Penelitian dan Review Literatur Bidang Ilmu Agronomi ISSN print $2503-1279$

ISSN online $2581-1606$

menjadi tersedia dan diserap oleh tanaman kedelei, sehingga pemberian bahan organik yang dikombinasi dengan pupuk anorgaik dalam penelitian ini dapat meningkatkan pertumbuhan dan hasil tanaman kedelei.

\section{KESIMPULAN}

Berdasarkan pengamatan dari hasil percobaan yang telah diuji dapat ditarik beberapa kesimpulan sebagai berikut; 1) Pemberian bahan organik masukan rendah pada tanaman kedelai memberikan pengaruh yang lebih baik terhadap pertumbuhan dan hasil tanaman kedelai yang disertai dengan cara aplikasi pemupukan yang tepat. 2) Pemberian bahan organik sebanyak 5 ton $\mathrm{ha}^{-1}$ yang diiringi dengan pemberian pupuk $\mathrm{N}, \mathrm{P}$, dan $\mathrm{K} 2 / 3$ dosis saat tanam dan $1 / 3$ dosis saat memasuki fase reproduktif yang disertai pemberian pupuk daun pagi dan sore hari memberikan hasil tertinggi pada variabel tinggi tanaman $(57,83 \mathrm{~cm})$, jumlah klorofil $11,99 \mu \mathrm{g} / \mathrm{cm}^{2}$ luas daun dan kandungan $\mathrm{N}$ daun $6,21 \%$, hasil tanaman 3,07 ton ha $^{-1}$ serta bobot 100 butir biji $15,12 \mathrm{~g}$, kecuali pada variabel pengamatan umur berbunga, mengalami perlambatan dibanding cara aplikasi pemupukan lainnya. 
Jurnal Media Pertanian Vol. 4 No. 1 Tahun 2019 Hal. 26 - 37

Media Komunikasi Hasil Penelitian dan Review Literatur Bidang Ilmu Agronomi

\section{DAFTAR PUSTAKA}

Bertham, Y. H., 2002. Respon tanaman kedelai (Glycine max (L.) Merrill) terhadap pemupukan Fosfor dan kompos jerami pada tanah Ultisol. Jurnal Ilmu-Ilmu Pertanian Indonesia, 4(2): 78-83.

Budhi, G. S., dan Mimin, A., 2010. Swasembada Kedelai. Antara Harapan dan Kenyataan. Forum Penelitian Agro Ekonomi. 28 (1): 55-68.

Dinas Pertanian Tanaman Pangan, 2015. Laporan Tahunan Pengembangan Tanaman Pangan Provinsi Jambi, Jambi.

Franzen, D.W. 1999. Soybean Soil Fertility. File://I:\Adopt Soil\%20fertility. htm, Hal:1-9.

Hardjowigeno, 2010. Ilmu Tanah. Akademika Pressindo, Jakarta.

John R. F., and L. H. David. 2001. Soybean yield response to reproductive stage soil-applied Nitrogen and foliar-applied Boron. Agron. J. 93: 1200-1209.

Kastono, D., 2005. Tanggapan pertumbuhan dan hasil kedelai hitam terhadap penggunaan pupuk organik dan biopestisida gulma siam. Jurnal Ilmu-Ilmu Pertanian, 12(2): 103-116.

Margiati S., R. A. Wiralaga, dan M. Fitriana, 2014. Takaran beberapa bahan organik terhadap pertumbuhan dan produksi tanaman kedelai (Glicine max (L.) Merril) pada tanah Ultisol. Prosiding Seminar Nasional Lahan Suboptimal, Hal. 29-37.

Prasetyo, B. H., dan D. A. Suriadikarta, 2006. Karakteristik, Potensi, dan Teknologi Pengelolaan Tanah Ultisol untuk Pengembangan Pertanian Lahan Kering di Indonesia. Jurnal Litbang Pertanian. 25 (2): 39-46.

Pusat Penelitian Tanah dan Agroklimat, 2011. Rekomendasi pemupukan tanaman kedelai pada berbagai tipe penggunaan lahan. Bogor.

Rosmarkam, A., dan N. W. Yuwono. 2002. Ilmu Kesuburan Tanah. Penerbit Kanisius, Jakarta.

Sri Mulatsih, W. Q. Mugnisjah, D. Sopandie, dan K. Idris, 2000. Pengaruh waktu dan cara pemberian $\mathrm{N}$ sebagai pupuk tambahan terhadap pertumbuhan dan hasil kedelai (Glycine max (L.) Merr) pada budidaya basah. Bul. Agron (1): 9-14.

Subagyo, H., N. Suharta, dan A.B. Siswanto. 2000. Tanah-tanah pertanian di Indonesia. Hal. 21-66 dalam Sumber Daya Lahan Indonesia dan Pengelolaannya. Pusat Penelitian Tanah dan Agroklimat, Bogor.

Taufiq, A., dan T. Sundari, 2012. Respon Tanaman Kedelai Pada Lingkungan Tumbuh. Buletin Palawija, 23: 13-26.

Zamski, E., 1996. Anatomical and Physiological Characteristic of Sink Cells. In E. Zamski and A. A. Schaffer (Eds). Photoassimilate Distribution in Plants and Crops; Source-Sink Relationships. Marcel Dekker, Inc.

Zapata F., S. K. A. Danso, G. Hardarson, M. Fried, 1987. Time course of Nitrogen fixation in field grown using Nitrogen. Agron. J. 79: 172-176. 